\title{
The Behavioral Repertoire of the Gastric Mill in the Crab, Cancer pagurus: An in situ Endoscopic and Electrophysiological Examination
}

\author{
Hans-Georg Heinzel,' James M. Weimann,,a and Eve Marder ${ }^{2}$ \\ 'Department of Zoology, University of Bonn, 5300 Bonn, Germany and 'Biology Department, Brandeis University, \\ Waltham, Massachusetts 02254
}

\begin{abstract}
Simultaneous endoscopic and electrophysiological recordings were used to observe the behavior of the gastric mill complex while recording the motor output of the stomatogastric ganglion (STG) in intact crabs. In the crab STG, many pattern-generating neurons are able to fire in several distinct rhythmic motor patterns. Specifically, many neurons can switch between firing in time with the rapid pyloric rhythm to firing in time with the slower gastric mill rhythm (Weimann et al., 1991). We now correlate behaviorally relevant movements of the gastric mill with some of the modifications of neuronal firing patterns previously characterized using in vitro STG preparations. The intracellular and extracellular recordings from the intact crab are largely indistinguishable from those obtained from in vitro preparations. For the first time, we describe the movements that result as neurons switch their activity patterns associated with activation of the gastric mill rhythm. Extracellular stimulation and intracellular depolarization of individual motor neurons is used to determine the relationship between frequency of firing and movement in behaving animals.
\end{abstract}

[Key words: stomatogastric ganglion, movement, crustacean, video analysis]

The stomatogastric nervous system has provided numerous insights into the mechanisms of pattern generation in rhythmic neural networks (Harris-Warrick and Marder, 1991; Selverston and Moulins, 1987). Work on isolated, in vitro preparations has demonstrated that each of the large number of different modulatory substances present in inputs to the stomatogastric ganglion (STG) produces a different variant of the motor patterns produced by the STG (Marder and Hooper, 1985; Marder and Weimann, 1992). Early work focused on modifications of the fast pyloric rhythm (Marder and Nusbaum, 1989) and the slower gastric mill rhythm (Heinzel and Selverston, 1988) produced by the STG. More recently, it has been shown that different modulatory environments can change synaptic efficacy, plateau

Received Apr. 20, 1992; revised Oct. 21, 1992; accepted Oct. 27, 1992.

We are grateful to Ms. Ingrid Anders and Dr. Hartmut Böhm for help with the video analysis, and Dr. Joseph Ayers for his generous advice and software support for the video and computer setup. We thank Ms. Joan McCarthy for help with manuscript preparation. This work was supported by NIH Grant NS17813, NATO

Travel Award 0540/86, the Human Frontier Science Program, and the German Research Foundation (HE1118).

Correspondence should be addressed to Dr. Eve Marder at the above address.

apresent address: Department of Biological Sciences, Stanford University, Stanford, CA 94305.

Copyright (C) 1993 Society for Neuroscience $0270-6474 / 93 / 131793-11 \$ 05.00 / 0$ properties, or endogenous oscillatory properties resulting in major regrouping of STG neurons into new operational networks (Hooper and Moulins, 1989; Dickinson et al., 1990; Katz and Harris-Warrick, 1991; Meyrand et al., 1991; Weimann et al., 1991; Marder and Weimann, 1992).

The richness of the modulatory changes seen in in vitro preparations often leads to the question of whether this richness is somehow an artifact of the in vitro preparation. Indeed, it is possible that the physical constraints and sensory feedback found in the intact animal might lead to much less flexible motor outputs than those produced in vitro. Therefore, one of the motivations underlying the present work is to determine whether several of the neuromodulatory changes that are found in in vitro preparations are seen in intact animals, and whether these are likely to have discrete, behaviorally significant roles.

Several laboratories have used various techniques to record either motor patterns or movements in the stomatogastric nervous system of intact behaving animals. EMGs (Powers, 1973; Hartline and Maynard, 1975; Rezer and Moulins, 1983, 1992) and extracellular (Morris and Maynard, 1970; Hermann, 1979a,b) and intracellular recordings (Hermann and Dando, 1977) have been used to examine the gastric and pyloric rhythms in intact or minimally dissected animals. Although these techniques allow the motor patterns in intact or almost intact animals to be recorded, they do not provide information about the actual movements associated with motor patterns. Small changes in motor patterns may produce appreciably different movements, or changes in motor patterns that appear dramatic may produce relatively little change in movement because of the nonlinear processes between patterns of activity and movement in a complex three-dimensional structure such as the foregut.

This limitation was partially overcome when direct observation of the three gastric teeth was achieved by inserting a narrow endoscope through the esophagus of the spiny lobster Panulirus interruptus (Heinzel, 1988a,b; Boyle et al., 1990). These endoscopic observations have greatly increased our understanding of the complex movements of the crustacean foregut. However, in these previous studies, movements of the medial and two lateral teeth were not directly correlated with recordings of the gastric motor neurons. Therefore, we were unable to assess directly which of the changes in motor patterns were likely to produce different movements.

We now combine endoscopic and electrophysiological recordings to associate the movements of the gastric teeth, the accessory teeth, and the cardiopyloric valve with the activity of STG motor neurons. We examined the gastric mill complex of the crab Cancer pagurus for several reasons. The gastric mill teeth are easily observed with an endoscope. Moreover, the 

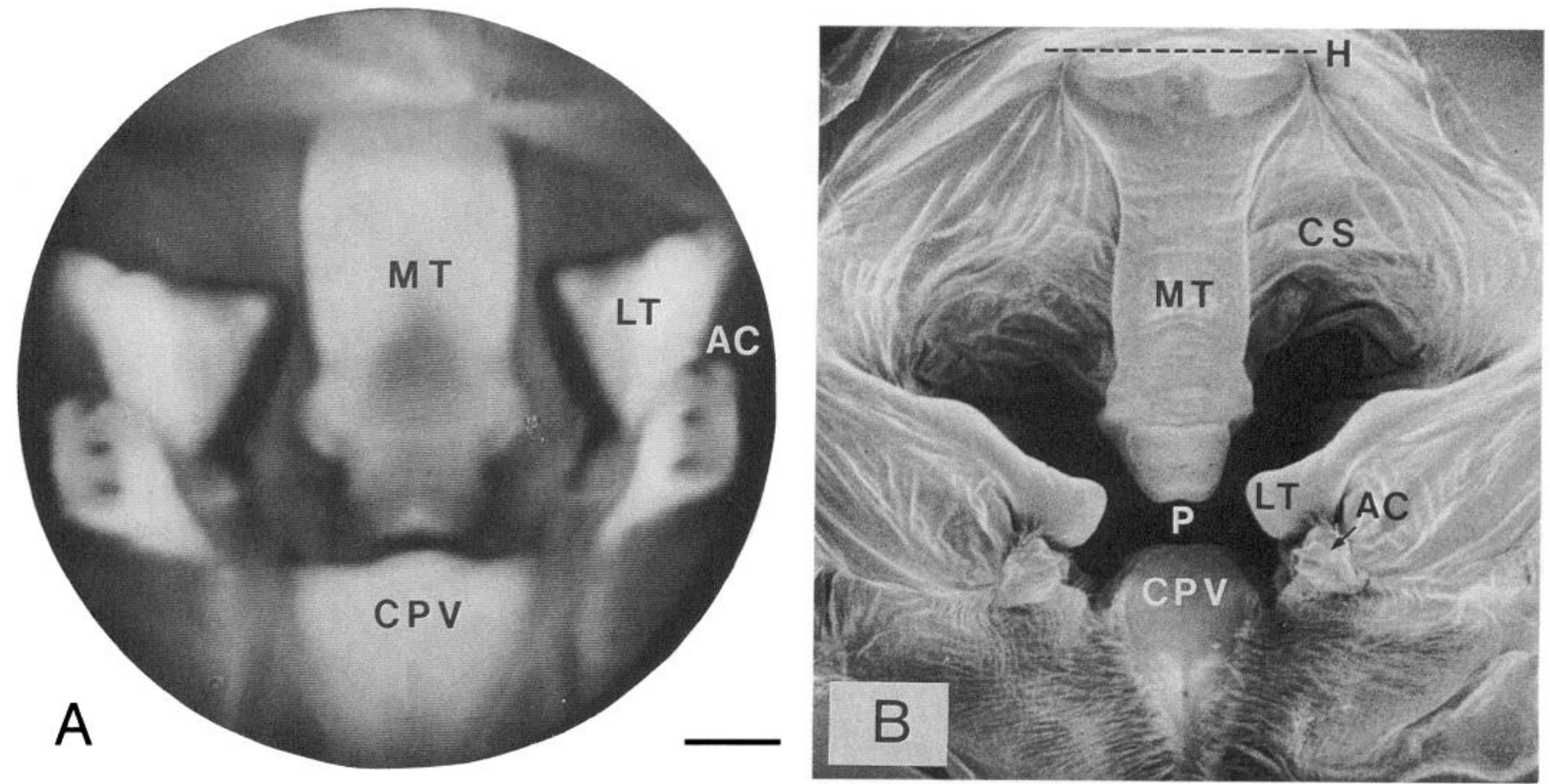

Figure 1. View of the stomach. A, Endoscopic view of the stomach of a large Cancer pagurus. B, Scanning electron micrograph of the same view of stomach from a small Cancer borealis. Crabs with a carapace diameter of $<2 \mathrm{~cm}$ were used to allow a complete view of the stomach. Note rows of hairs in the cardiopyloric valve $(C P V)$ pointing toward the pyloric chamber $(P) . M T$, medial tooth; $L T$, lateral teeth; $A C$, accessory teeth; $C S$, cardiac sac; $H$, hinge of medial tooth. Scale bar: $2 \mathrm{~mm}$ for $A ; 1 \mathrm{~mm}$ for $B$.

anatomy of the crab allowed intracellular and extracellular recordings from the STG with only minimal dissection of the carapace and underlying hypodermis.

Simultaneous recordings of the movements of the gastric mill and STG motor patterns show that the motor patterns in the intact animal are similar to those from in vitro preparations. In this article we focus on movements that are produced as STG neurons switch their activity patterns from pyloric time to gastric time (Weimann et al., 1991). We now show that switches in neuronal firing patterns described for the isolated in vitro preparation also occur in the intact behaving crab. Importantly, some of the most difficult to understand changes in neuronal firing patterns are now seen to have simple behavioral roles.

Some of these data have appeared in abstract form (Heinzel and Weimann, 1990).

\section{Materials and Methods}

Animals. Cancer pagurus were obtained from a marine food supplier in Paris. The crabs were kept in aerated seawater tanks at $13^{\circ} \mathrm{C}$ for several days. Sixty-five crabs (44 females and 21 males) weighing $0.5-$ $1.5 \mathrm{~kg}$ (outer carapace width, $10-18 \mathrm{~cm}$ ) were used for recordings. Five small Cancer borealis (carapace, $\sim 1 \mathrm{~cm}$ ) were used for scanning electron microscopy. The experiments described in Figures $3 A$ and $4 A$ were obtained from male Cancer borealis (Neptune Lobster and Seafood Co., Boston, MA).

Endoscope. A flexible endoscope (model TBF-1.4-50, made by Hinze $\mathrm{GmbH}$ ) with an outside diameter of $1.4 \mathrm{~mm}$ and an $130^{\circ}$ field of view was inserted using a mouth holder (6-mm-diameter tubing with four smaller-diameter tubes glued into it). The endoscope was inserted into the central tube while two other tubes carried the inflow and outflow of the saline stream used to flush the digestive juices that impede viewing of the teeth. A small syringe was introduced into the fourth tube to remove air bubbles that accumulated near the medial tooth and distorted the image of the teeth. A hole was drilled into the main tube and connected with plastic tubing to a syringe. A piece of balloon was sealed over this hole; air was forced into this balloon, causing it to expand and secure the mouth tube in the esophagus. This also allowed a tight seal of the stomach so that increasing the rate of the saline inflow led to inflation of the stomach, thus permitting better viewing of the teeth.

The endoscope was inserted to give a clear view of the three gastric teeth, the accessory teeth, and the cardiopyloric valve (Fig. $1 \mathrm{~A}$ ). A similarly oriented scanning electron microscopic view of the gastric mill is shown in Figure $1 B$. The top of Figure $1 B$ is the anterior part of the gastric mill where the hinge (H; ossicle II) of the medial tooth (MT) is located. The lateral (LT) and accessory (AC) teeth are found on each side of the medial tooth. On the ventroposterior margin of the gastric mill is the cardiopyloric valve (CPV) with the clearly visible minute hairs oriented toward the pylorus $(\mathrm{P})$. Because the endoscope has a $130^{\circ}$ field of view, the dorsal teeth and the ventral cardiopyloric valve appear in the same plane. The dorsal view of the teeth is seen in Figure $2 B$, and the ventral view in Figure $2 E$.

Preparation. The crabs were held in a small aquarium containing circulating filtered, aerated, and chilled $\left(13^{\circ} \mathrm{C}\right)$ artificial seawater, to allow the crab to respire normally while keeping the dorsal surface of the carapace above the water line. The carapace was cut open with a dental drill. A thin layer of epoxy glue was applied to the carapace outside of the cut.

Before the cut portion of the carapace was removed, a Vaseline well was formed on the dried epoxy glue on the carapace surrounding the area where the carapace would be removed (Fig. $2 A$ ). This allowed separate perfusion of the musculature and nervous system (Fig. $2 B$ ) with crab saline $(440 \mathrm{~mm} \mathrm{NaCl}, 11.3 \mathrm{~mm} \mathrm{KCl}, 13.3 \mathrm{~mm} \mathrm{CaCl}, 26.3 \mathrm{~mm}$ $\mathrm{MgCl}_{2}, 11.0 \mathrm{~mm}$ Trizma base, 5.2 mM maleic acid, $\left.\mathrm{pH} 7.4-7.5\right)$ at 13$15^{\circ} \mathrm{C}$. Exposed tissue was superfused at $10-25 \mathrm{ml} / \mathrm{min}$. Endoscopic observations during dissection showed that the movements of the stomach were not perturbed by carapace removal.

The STG is suspended in a major artery. To maintain the flow of oxygenated saline throughout the animal after opening the artery for recordings, the artery was severed posterior and anterior of the STG. The posterior artery was clamped with a small spring-wire clamp, and the anterior portion was ligated to the outflow line of a peristaltic pump. The animal was then perfused with chilled crab saline.

Extracellular recordings. Extracellular recordings from the major nerves exiting the STG were made with hook-cuff electrodes using $40 \mu \mathrm{m}$ varnished stainless steel wire (Fig. $2 C$ ). Pieces of glass tubing (1.25 mm o.d., $0.50 \mathrm{~mm}$ i.d.) were ground to a conical shape at one end, and then 


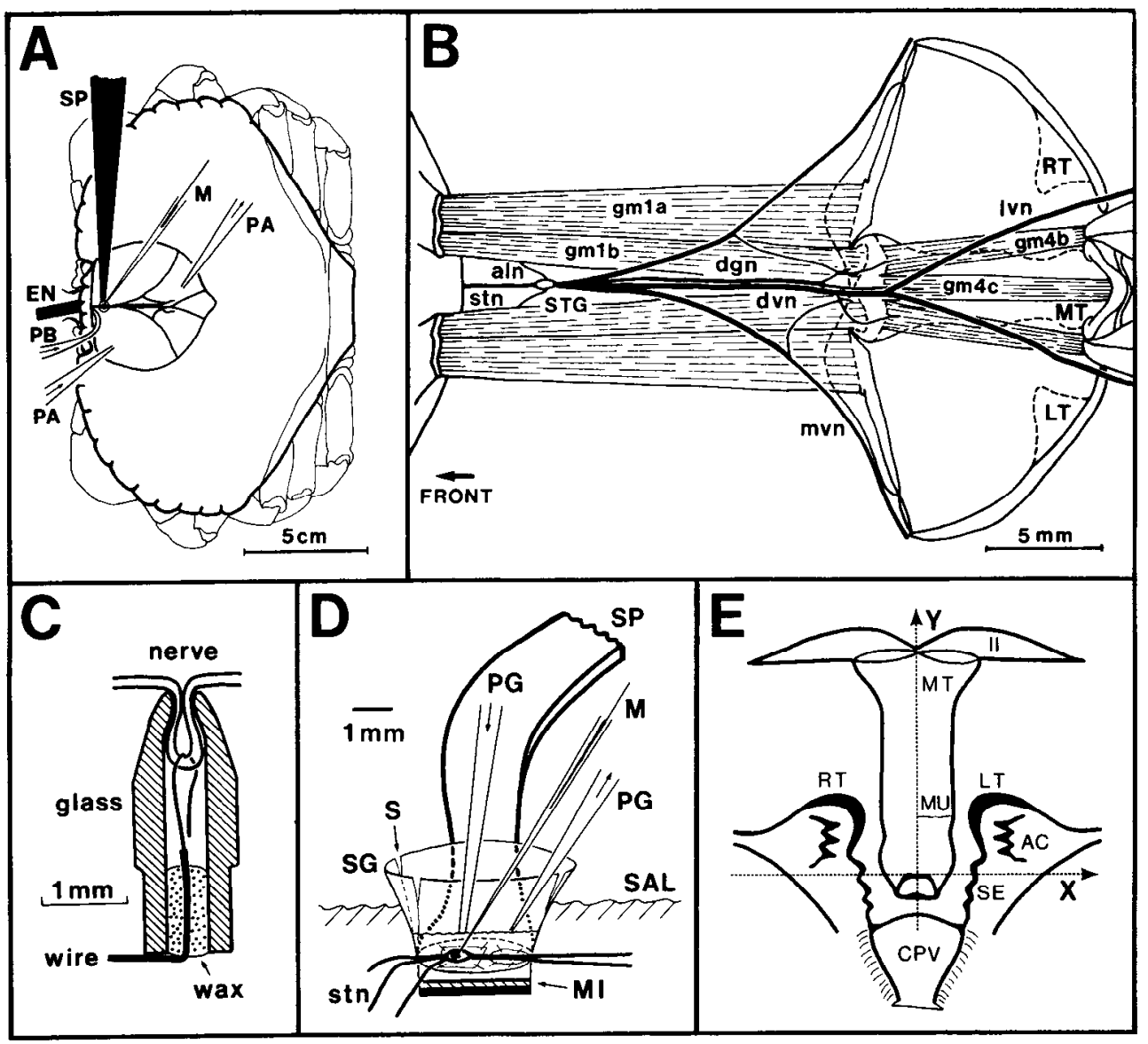

Figure 2. Protocol. A, Crabs were stabilized in animal holder and placed in a small aquarium. The carapace was opened and the nervous system exposed. The STG was stabilized on a supporting platform $(S P)$. Brain $(P B)$ and whole animal $(P A)$ were perfused with cold saline. A flexible endoscope $(E N)$ was inserted into the cardiac sac, enabling viewing of the gastric mill. $B$, Dorsal view of stomach highlighting muscles and nerves $M T, L T$, and $R T$ (medial, left, and right lateral teeth, respectively). Extracellular nerve recordings were made from the $d g n, m v n$, and $d v n$. aln, anterior lateral nerve; $l v n$, lateral ventricular nerve; stn, stomatogastric nerve. $\mathrm{C}$, Hook-cuff electrodes used for nerve recordings. $D$, The STG was supported on a platform $(S P)$ coated with Sylgard $(S G)$ over a mirror $(M I)$. Thin Sylgard walls with slits $(S)$ for nerves allowed perfusion of the STG alone $(P G)$. Standard microelectrode $(M)$ techniques were used. $E$, Schematic of teeth as seen through the endoscope. $M U$, Half-width of medial tooth; $S E$, serrated edged of lateral tooth; $X$ and $Y$, coordinate system for movement plots; $I I$, ossicle II. fire polished to make the tip contract to an inner diameter twice that of the desired nerve. The wire was inserted and the large-diameter hole sealed with melted dental wax. The wire exiting the polished end was stripped of the varnish and bent into a hook $(200-300 \mu \mathrm{m})$. This floating electrode was placed near the nerve (Fig. $2 B$ ), and the stripped end of the wire was looped around the nerve and pushed back into the narrow polished end of the glass electrode. The wire was then grasped near the wax plug, and the hooked wire and nerve were drawn into the glass electrode where the connective tissue of the nerve electrically sealed the electrode. These electrodes moved with the stomach without obstructing the intracellular recordings.

The identity of the neurons firing in the motor nerves is known from extensive previous work on the crab stomatogastric nervous system in which motor nerve recordings were combined with intracellular recordings from somata and from muscles innervated by these neurons (Hooper et al., 1986; Weimann et al., 1991).

Intracellular recordings. A platform (Fig. $2 D$ ) made from rigid titanium was placed below the STG. A mirror made by gold plating a piece of coverslip was glued to the bottom of the platform. A thin layer of Sylgard was applied over the mirror, to which the STG was pinned. A Sylgard funnel was constructed by dipping a conical metal piece into a pool of Sylgard and allowing it to harden. The funnel was then glued to the platform, and four slits were cut for the nerves exiting the STG. Once the platform was in position below the STG, the nerves were placed into the precut slits, which were sealed with Vaseline. A saline inflow $(15 \mathrm{ml} / \mathrm{min})$ tube was glued to the platform. The outflow tube was mounted on a micromanipulator allowing control of the saline level around the ganglion, and provided a superfusion system for the STG separate from that for the rest of the animal.

Microelectrodes filled with 2 M K-acetate (20-30 M $\Omega$ ) were mounted on Narishige micromanipulators and used to record from somata after desheathing the STG.

Data analysis. The endoscopic image of the foregut was monitored by a sensitive black-and-white video camera (model ITC-48, Ikegami Co.). A clock signal (model VTG-33, For-A Inc.) was inserted for later identification of video frames. Another video camera captured the in- tracellular and extracellular recordings from an oscilloscope. The signals from both video cameras were merged with a video screen splitter (model SSI-5, Ikegami Co.) and displayed on a high-resolution monitor and recorded on a Sony Video 8 PAL recorder (model EVS-850P). The audio tracks of the video recorder were used for extracellular nerve signals. Extracellular and intracellular recordings and the video clock signal were stored on a seven-channel FM recorder (Racal).

The movement profiles of the lateral teeth were plotted in $\mathrm{x}, \mathrm{y}$-coordinates. The position of the tips of the teeth was measured on the video screen in every second frame of a data sequence. The $x$ - or $y$-coordinate was plotted versus time (Fig. $2 E$; see Heinzel, 1988a,b, for a complete description). In some experiments a video frame grabber (Quick Capture, Data Translation, Inc.) was used with NIH IMAGE 1.40 software on a Macintosh IIfx computer.

\section{Results}

\section{The gastric mill rhythm}

The gastric mill rhythm controls the movements of the two lateral teeth and one medial tooth. Robust gastric rhythms have periods of approximately 5-10 sec, and several variants of gastric mill rhythms have been described (Mulloney and Selverston, 1974a,b; Heinzel, 1988a,b; Heinzel and Selverston, 1988). In gastric rhythms the two lateral teeth move in and out and the medial tooth moves back and forth at $90^{\circ}$ to the lateral tooth movement (Hartline and Maynard, 1975). Variations in the relative timing of the lateral and medial tooth movements result in some of the variations of the gastric rhythms described. Heinzel $(1988 \mathrm{a}, \mathrm{b})$ described two characteristic forms of the gastric mill movements. In the "cut and grind" movement, the lateral teeth close before the medial tooth retracts. In the "squeeze" movement, the lateral teeth close while the medial tooth retracts. 
A IN VITRO
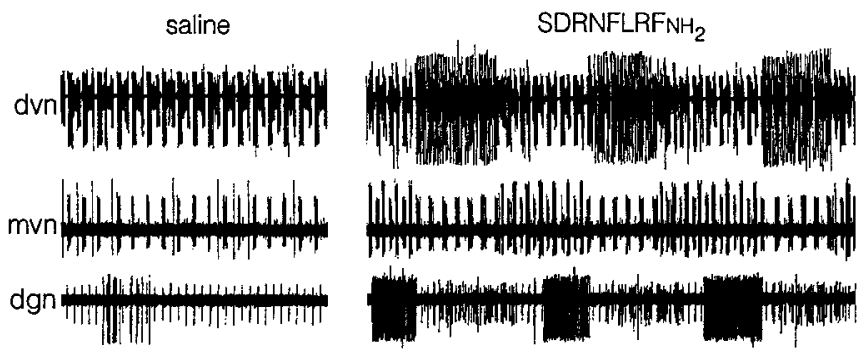

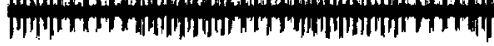

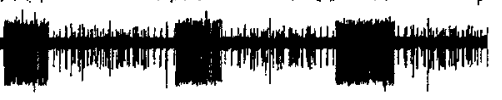

$5 \mathrm{~s}$
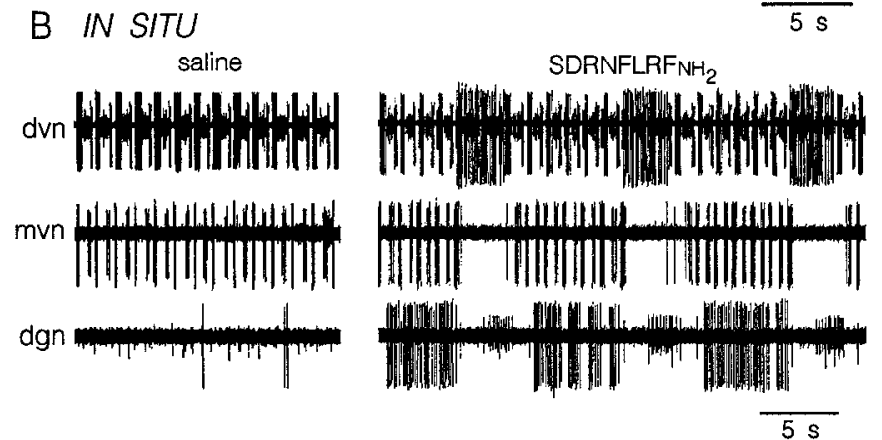

Figure 3. SDRNFLRFamide activates gastric rhythm. A, In vitro preparation of $C$. borealis. Control shows pyloric activity. LP, PY, and PD are large, small, and medium spikes, respectively, firing in bursts in the $d v n$. IC (small spikes) and VD (large spikes) are seen in the mvn. After bath application of SDRNFLRFamide $\left(10^{-7} \mathrm{M}\right)$, gastric activity is initiated. DG (large spikes in dgn) and GM (small spikes in dgn) are firing out of phase. Notice that VD and IC are recruited into the gastric rhythm. The large spikes on $d v n$ are from LG and the small tonic spikes on dgn are from the sensory neuron AGR (anterior gastric receptor). $B$, Comparable recordings from an in situ preparation of $C$. pagurus.

These different movements were correlated with variations in the relative phasing of the motor neurons that innervate the muscles of the gastric mill (Nagy et al., 1988).

Comparison of in vitro and in situ recordings

Early work on several species of decapods had shown striking similarities between recordings of the motor patterns from intact or minimally dissected animals and from isolated stomatogastric nervous system preparations (Morris and Maynard, 1970; Hartline and Maynard, 1975; Hermann and Dando, 1977). Heinzel and Selverston (1988) measured the effects of two modulators, octopamine and proctolin, on gastric mill motor patterns produced by in vitro preparations and then attempted to associate these with movements visualized with the endoscope (Heinzel, 1988a,b). We now compare directly motor patterns and their associated movements with in vitro recordings during spontaneous activity and in the presence of several different modulatory substances.

Two peptides from the FMRFamide family, SDRNFLRFamide and TNRNFLRFamide, initiate gastric activity in the isolated crab STG (Weimann, 1992). Figure 3 provides a direct comparison of the effects of one of these peptides, SDRNFLRFamide, on in vitro and in situ preparations. In the absence of peptide (Fig. 3A, $B$, saline) the recordings of the dorsal ventricular nerve (dvn), medial ventricular nerve (mvn), and dorsal gastric nerve (dgn) (which monitor the pyloric and gastric motor patterns) show that only a pyloric motor pattern is present [see the fast rhythm on the dvn in which the lateral pyloric (LP), pyloric (PY), and pyloric dilator (PD) neurons fire in alterna-
A

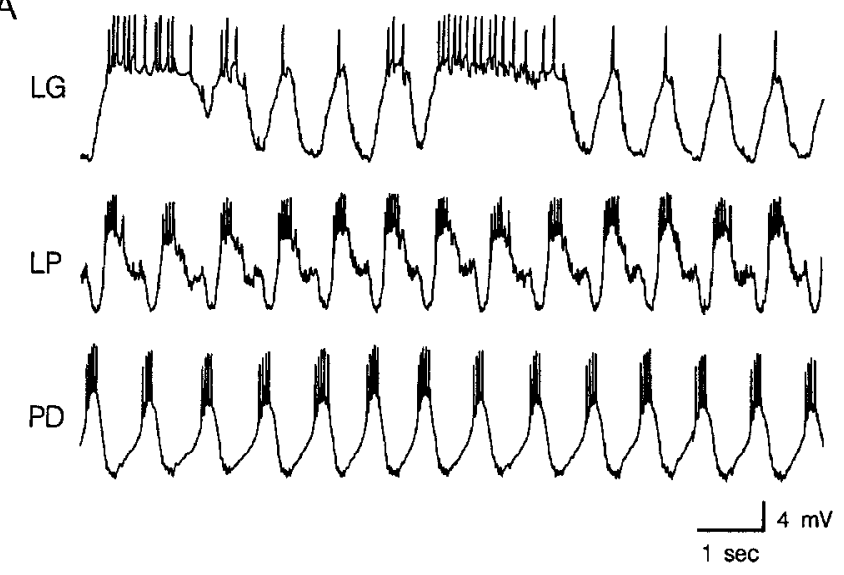

B

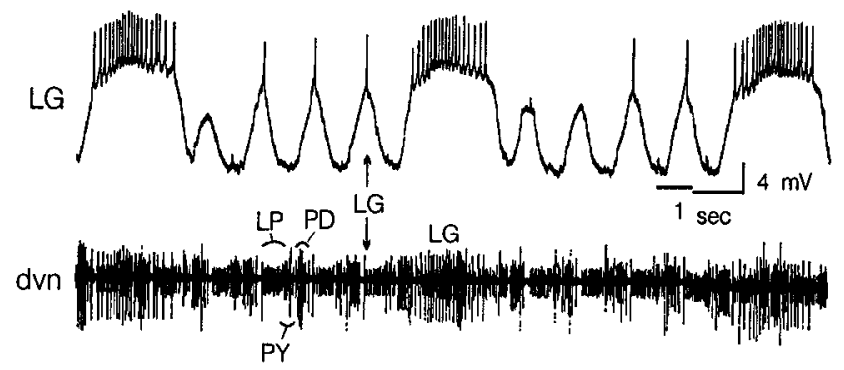

Figure 4. Hybrid LG activity in both in vitro and in situ preparations. $A$, Simultaneous intracellular recordings from an in vitro preparation show the gastric $L G$ neuron switching between long gastric bursts and shorter pyloric-timed bursts that are phase locked to pyloric $L P$ and $P D$ neurons (most hyperpolarized potential: $L G,-62 \mathrm{mV} ; \mathrm{LP},-58$ $\mathrm{mV} ; \mathrm{PD},-60 \mathrm{mV}) . B$, Spontaneous gastric/pyloric switching of $L G$ recorded from an in situ preparation is very similar to that seen in $A$ $(\mathrm{LG},-56 \mathrm{mV})$.

tion]. After application of SDRNFLRFamide (Fig. $3 A, B$ ) a gastric rhythm was initiated [as monitored by bursts of the dorsal gastric (DG) neuron on the dgn]. Note also that the inferior cardiac (IC) neuron and the ventricular dilator (VD) neuron (the two units on the mvn), both of which were previously characterized as pyloric neurons, switched into gastric-timed activity patterns in the presence of peptide (Weimann et al., 1991; Fig. $3 A, B)$. The differences seen between the SDRNFLRFamide recordings in the two cases (e.g., the absence of the IC activity in the in situ case) are also seen in peptide applications in different in vitro experiments (Weimann, 1992). These data are representative of the results from 19 applications of SDRNFLRFamide in 12 animals.

We applied several other neuromodulators known to influence STG motor patterns in in vitro preparations to the in situ preparation. As is the case for SDRNFLRFamide, similar results were obtained in in situ recordings to those previously obtained in in vitro recordings. Proctolin $(n-20)$ applied to in situ preparations increased the pyloric frequency (in slow rhythms, $<1$ Hz) and the number of action potentials in each LP burst (see also Fig. 9A). Proctolin also initiated or enhanced gastric activity in the intact crab in six preparations, as had previously been demonstrated (Marder and Nusbaum, 1989; Heinzel, 1990a,b). The results obtained with proctolin resemble closely those previously described in in vitro experiments in crabs (Marder and Hooper, 1985; Marder et al., 1986; Nusbaum and Marder, 

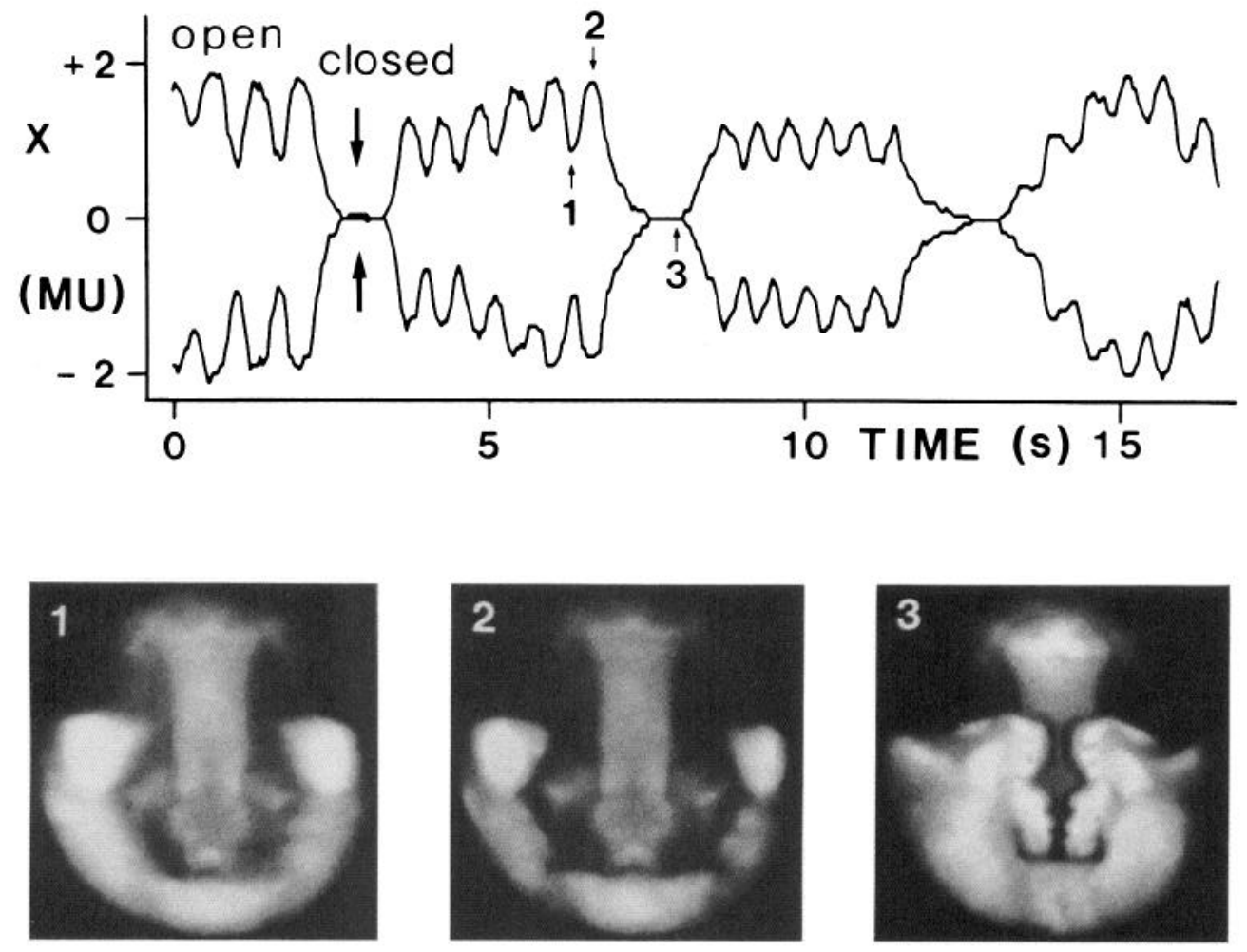

Figure 5. Intact crab with endoscope inserted into stomach shows strong pyloric and gastric movements of the lateral teeth. Top, Plot of the lateral position of the lateral teeth during three consecutive gastric bites with many interspersed pyloric bites. Bottom, three video frames taken at times 1,2 , and 3 of the top panel. 1, Position of the teeth during pyloric closure; 2 , during open phase (note that the teeth are farther from the midline); and 3, during gastric closure when teeth touch at the midline.

1989a,b; Weimann et al., 1990). (See Heinzel, 1988a,b, and Heinzel and Selverston, 1988, for a comparison of the in vitro and intact lobster.)

The effects of the muscarinic agonist pilocarpine (19 applications in 15 animals) (Marder and Hooper, 1985; Weimann et al., 1990; Marder and Weimann, 1991) and crustacean cardioactive peptide (Dircksen and Keller, 1988; Stangier et al., $1988)$ applied to the STG $(n=5)$ were also similar to those previously described in in vitro preparations of crabs (Weimann et al., 1992). The above comparisons were not intended to provide a detailed description of the effects of these modulators on the behaving crab. Rather, we wished to determine whether the effects were qualitatively similar to those seen in vitro, thus making it possible to study the movements that are likely to be associated with each modulated state. Moreover, these data provided us confidence that the experimental perturbations associated with making simultaneous physiological and movement recordings were not themselves producing significant perturbations of the preparations.

\section{Pyloric-timed movements of the lateral teeth}

One of the most puzzling results from recent work on the crab STG was the finding (Weimann et al., 1991) that many of the neurons of the STG can markedly change their patterns of activity. Specifically, many of the neurons that innervate muscles that were thought to function only to move the pylorus were found to fire in time with the rapid pyloric rhythm under some conditions, but were also found to fire in time with the slower gastric rhythm under other conditions. Additionally, many neurons that innervate muscles thought previously to function only to move the teeth of the gastric mill were found to fire in time with the rapid pyloric rhythm (Weimann et al., 1991). It was not clear from these in vitro experiments whether the same switches in firing patterns occurred in the intact, behaving an- imal. Moreover, the potential behavioral consequences of these switches were unclear. The combined endoscope and electrophysiological recordings illuminate this situation.

In Figure 4 we compare recordings from the lateral gastric (LG) neuron in vitro and in situ, and show that the LG neuron produces the same complex patterns of activity in the two conditions. Figure $4 A$ displays simultaneous intracellular recordings from the LG neuron and two pyloric rhythm neurons, the LP and PD neurons, in an in vitro preparation. Note that the LG neuron was firing in a hybrid rhythm in which long (1-2 sec) gastric bursts alternated with three or four pyloric-timed bursts. Figure $4 B$ shows an intracellular recording from the LG neuron made in an in situ preparation. The pyloric rhythm is seen in the extracellular dvn recording. As in Figure $4 A$, the LG neuron was firing in a hybrid rhythm in which long bursts alternated with more rapid pyloric-timed activity.

New insight into the functional consequences of the hybrid rhythm displayed by the LG and other neurons comes from endoscopic examinations of the movements of the crab gastric mill teeth. Figure 5 shows sequences of activity in which typical 1-2 sec bouts of gastric activity cause the lateral teeth to move forward and meet at the tips, followed by the closure of the serrated edges of the lateral teeth over the medial tooth (Fig. 5, bottom, panel 3). This has been termed the "cut and grind" mode of chewing (Heinzel, 1988a). The position of both lateral teeth with respect to the midline during three cycles of a gastric rhythm is plotted in the top portion of Figure 5 . The fully closed position of the lateral teeth is at the midline, while the fully opened position in this animal was $2 \mathrm{MU}$ from the midline (MU is half the width of the medial tooth). Three distinct positions are observed. First, between the longer gastric bursts the lateral teeth pump four or five times at a frequency characteristic of the pyloric time. Panel 1 shows the position of the lateral teeth in the partially closed state of one of the rapid movements. 


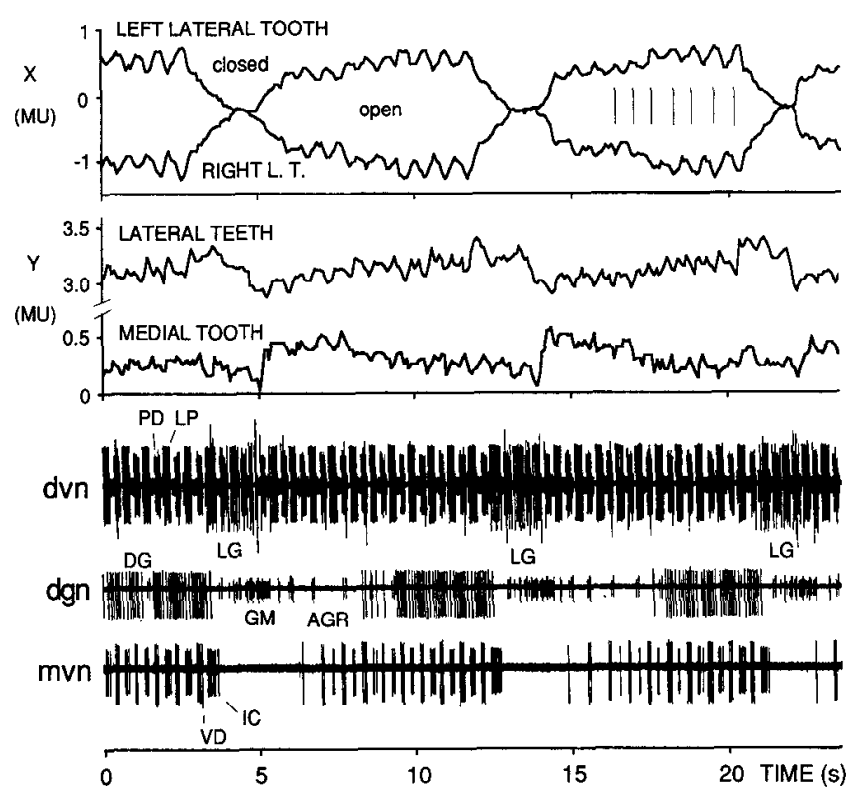

Figure 6. Simultaneous movements and motor patterns during gastric rhythm. Top panels are plots of sideward $(X)$ and frontal-caudal $(Y)$ movements of the tips of the two lateral teeth and the medial tooth that were produced by the motor patterns below. The pyloric rhythm is seen as the rapid alternation between the $L P$ and $P D$ neurons on the $d v n$. The gastric rhythm is characterized by the alternation between the $D G$ and $G M$ neurons shown on the $d g n$, as well as the groups of large $L G$ action potentials on the $d v n$. The $m v n$ carries the axons of the $V D$ and $I C$ neurons. The beginning of seven $I C$ bursts are marked between the two top traces (vertical bars) to illustrate their correlation with the small pumping movements of the lateral teeth. The $d g n$ also shows the small spike of a mechanoreceptor, the anterior gastric receptor $(A G R)$ neuron.

Second, after this partial closure the teeth are retracted to the fully open state (panel 2). This pumping motion, which appears to stir the contents of the gastric mill, is repeated five or six times before the complete closure of the lateral teeth occurs (panel 3). Not only do the tips of the teeth meet at the midline, but the posterior serrated edges also meet, executing the cut portion of the cut and grind.

To determine directly if the rapid movements seen in Figure 5 are actually produced by pyloric-timed activity, we simultaneously recorded movements and motor patterns. Figure 6 presents the movements of the lateral and medial teeth together with extracellular recordings that show the motor patterns that produced them. Note that the full closures of the lateral teeth are associated with long, gastric-timed bursts in the LG neuron. Additionally, each rapid, partial closure of the lateral teeth is in time with the pyloric rhythm. (The onset of the IC burst is shown in the vertical lines over the right part of the right lateral tooth recording.) In this particular experiment, the pyloric-timed closing of the lateral teeth was partially produced by pylorictimed activity in the IC neuron, as a cut of the mvn on one side produced an ipsilateral reduction of the movement (not shown).

To determine if the short pyloric-timed bursts in the LG and medial gastric (MG) neurons (such as those seen in the hybrid LG pattern in Fig. 4) were also sufficient to move the lateral teeth in pyloric time, in three preparations we recorded intracellularly from these neurons, and individually depolarized or hyperpolarized them while monitoring the position of the teeth (Fig. 7). Because we were only able to record intracellularly from one neuron at a time, the following paradigm was used. Although
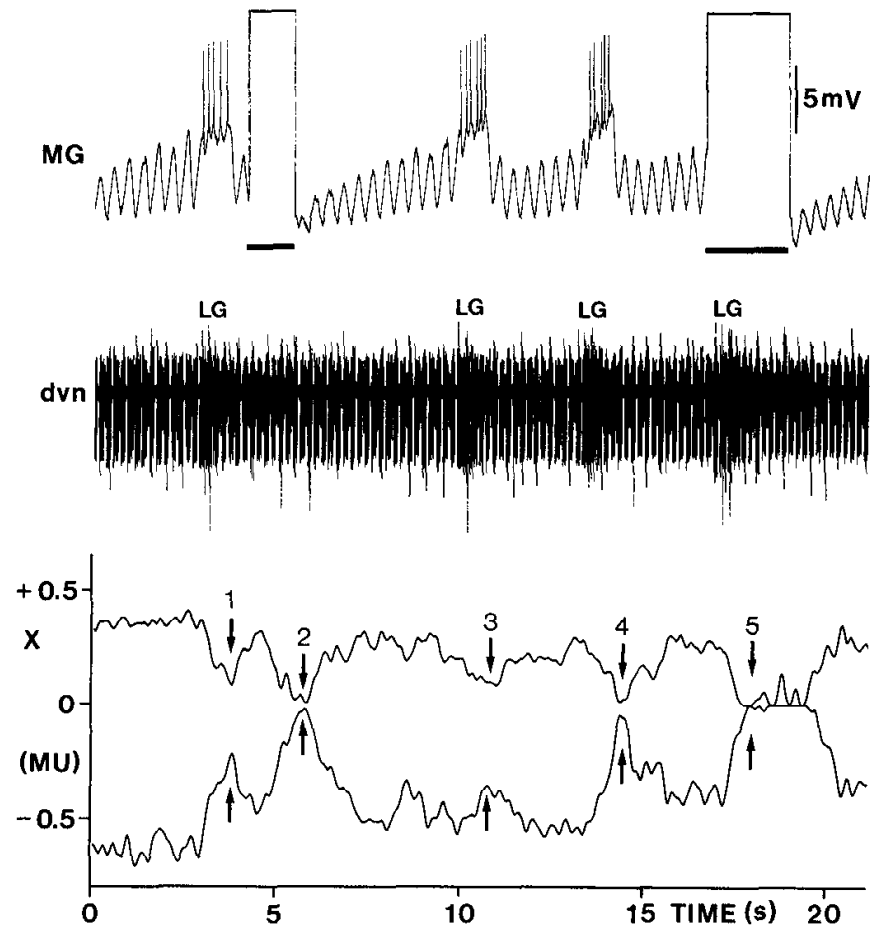

Figure 7. Both $M G$ and $L G$ can close the lateral teeth. $M G$ and $L G$ usually fire together and cause the lateral teeth to close (positions $l, 3$, and 4 show spontaneous weak activity in $M G$ associated with $L G$ activity). When $M G$ is depolarized (horizontal bar) without $L G$ firing (position 2), the lateral teeth close completely. When $M G$ is depolarized during an $L G$ burst (position 5), closure of the lateral teeth is stronger. (Most hyperpolarized potential of MG, $-52 \mathrm{mV}$ ).

the MG and LG neurons are electrically coupled and usually fire together, each can be induced to fire alone when depolarized shortly after a spontaneous burst (Fig. 7). Figure 7 illustrates five closures of the lateral teeth. In closure 1 both LG and MG fired spontaneously and a small movement ensued. The MG neuron was then depolarized (horizontal bar); LG did not fire during the depolarization. Because it was not possible to balance the bridge, the number of MG spikes could not be directly measured. Firing MG strongly without $L G$ produced a complete closure (closure 2) of the tips of the lateral teeth. Closure 5 was started by depolarizing MG, which induced the $\mathrm{LG}$ neuron to start firing, resulting in a strong prolonged closure of the lateral teeth. These and other observations lead to the conclusion that the $\mathrm{MG}$ neuron is involved in the closing of the tips of the lateral teeth. Short bursts of the LG neuron also close the tips of the lateral teeth. However, longer bursts cause the tips to meet at the midline first, which is then followed by the serrated edges of the lateral teeth meeting at the midline to produce the cut phase of the cut and grind.

When the LG and MG neurons fire in pyloric time or in a hybrid, pyloric/gastric pattern, they can fire from one to five spikes in each pyloric burst. Therefore, we were interested to determine the movements produced by bursts of pyloric-timed activity of different numbers of spikes per burst. To study this, in 10 preparations we stimulated the $\mathrm{dvn}$ at various frequencies (this gave more control than that achieved with intracellular stimulations), at thresholds sufficient to activate either the LG alone, or the LG and MG together. This is possible because the LG and MG axons routinely are the lowest-threshold units in 
the nerve. Figure $8 A$ shows a plot of the movements of the lateral teeth for three bursts of 4 spikes/burst of the LG alone, followed by successive stimulations of $L G$ and $M G$ together. Note that 4 spikes/burst of the LG produced a substantial movement, but the movements produced by activation of both the LG and MG were larger. Figure $8, B$ and $C$, shows the significance of facilitation and the previous history of activity for the movements produced. In Figure $8 B$ the dvn was stimulated to give 3 impulses/cycle. At the start of the sequence the teeth were open, and they steadily moved closer together with the next three bursts, until each pyloric burst brought them to an almost closed position. In Figure $8 C$ the dvn was stimulated twice with each pyloric burst. The first sequence of stimuli produced small closing movements. Then a continuous stimulation for about 5 sec to mimic along gastric-timed burst produced a complete closure of the teeth. Subsequently, the same pyloric-timed stimuli produced larger closing movements, as the teeth pumped inward and outward on a continuously opening trajectory. Figure $8 D$ shows a plot of the maximal amplitude of the closing movements produced by bursts consisting of increasing numbers of stimuli. As the number of action potentials/burst was increased, the closing movement increased from $20 \%$ closed to totally closed at 5 spikes/burst. Together, the data shown in Figures 7 and 8 indicated that even small numbers of pylorictimed spikes can produce behaviorally significant movements. Moreover, the amplitude of these movements depends critically on the dynamics of the ongoing rhythms.

In many preparations (either under control conditions or in the presence of low concentrations $\left(10^{-8} \mathrm{M}\right)$ of SDRNFLRFamide) the only neuron that fires in long gastric-timed bursts is the DG neuron. In these circumstances the LG and MG ncurons fired in pyloric time. The movements that result from this pattern of activity can be seen using the endoscope, and consist of rapid pyloric-timed "pumping" movements of the lateral teeth (as seen in Figs. 7, 8) while the medial tooth moved caudally toward the pylorus in a "battering ram" fashion. This is the first time that this behavioral sequence has been observed, and likely functions to move food into the pyloric chamber from the gastric mill. This "pyloric loading" behavior can be aided by movements of the cardiopyloric valve controlled by the IC and VD neurons.

\section{Functional role of IC neuron pyloric-gastric switching}

The IC and VD neurons move parts of the gastric mill and cardiopyloric valve. These two neurons are also involved in the movements of the accessory teeth, which are mechanically coupled to the lateral tecth and the cardiopyloric valve region. The resulting movements differ depending on the firing pattern of IC. When IC and VD fire in pyloric time, the accessory teeth and cardiopyloric valve pump quickly with small-amplitude inward-outward movements. Moreover, the lateral teeth can also be moved (Fig. 6). We have observed the behavior of the IC and VD neurons in the absence of food. However, we envision that the contractions due to the firing of the IC and VD neurons would move food into the pyloric chamber by the following mechanism. Contractions due to the firing of the IC neuron bring the rows of fine hairs along the cardiopyloric valve (Fig. $1 B$ ) closer together, pushing food particles toward the pylorus. Food not yet in the reach of the hairs could be moved toward them as the accessory teeth move in phase with the valve. The fine hairs could also keep the food particles in place during the VD driven opening phase of the valve.
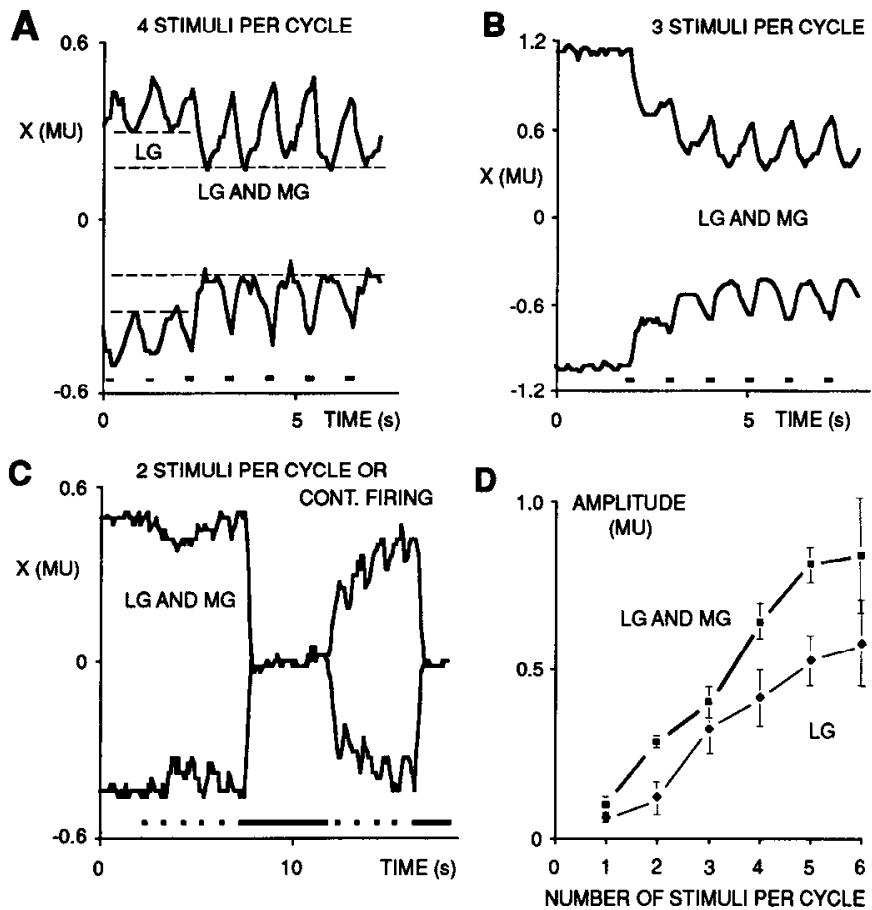

Figure 8. The movements of the lateral teeth produced by different numbers of $L G$ and $M G$ spikes. The axons of the $L G$ and $M G$ were stimulated in the dvn, either alone or together, to determine their individual contributions to the movements produced. $A$, The $L G$ was stimulated alone ( $4 \mathrm{stimuli} /$ cycle) for the first three bursts, and then $L G$ and $M G$ were stimulated for the next five bursts. The single stimuli within a burst (short bars) were given at $40 \mathrm{msec}$ intervals. $B$, Facilitation of $L G / M G$ movements during the onset of stimulation. $C$, The effects of mimicking a hybrid pyloric/gastric rhythm by an alternation of $1 \mathrm{~Hz}$ cycles and longer firing periods. Note the enhanced pyloric movements of the lateral teeth after the gastric-like stimulation. $D$, Plot of the amplitude of the lateral tooth movement as a function of the number of stimuli/cycle. Lower curve shows the $L G$ alone. Upper curve shows joint activation of hoth the $L$ Gand $M G$.

The IC neuron, traditionally considered a pyloric neuron, can also fire in time with the gastric rhythm. In the isolated nervous system, several of the pyloric neurons have been observed to switch to a gastric activity pattern upon initiation of a gastric rhythm either spontaneously or after application of modulatory substances (Weimann et al., 1991). Bath application of proctolin to the STG strongly activates the pyloric rhythm. As is the case in experiments done in vitro (Marder et al., 1986; Hooper and Marder, 1987; Nusbaum and Marder, 1989a,b), the proctolinactivated pyloric rhythm seen in situ is associated with long bursts of the LP neuron (Fig. 9A,B). After a few minutes in $10^{-6} \mathrm{M}$ proctolin, the IC neuron starts to produce long bursts of action potentials and fires in time with the gastric rhythm in both in vitro preparations (J. M. Weimann, unpublished observations) and the intact crab (Fig. 9B). The movements associated with this gastric activity of the IC neuron involve the cardiopyloric valve and the lateral teeth (movement panel of Fig. 9B).

In the case shown in Figure 9, the LG neuron was not firing action potentials, probably because it was damaged by penetration with a microelectrode. This made the analysis of the contribution of IC to the overall movement of the lateral teeth easier. In this experiment, the movement of the lateral teeth during the IC plateau was anterior and only a little toward the midline, which facilitated the analysis of IC-evoked movements of the lateral teeth. Therefore, only the y-axis is plotted in Figure 
A
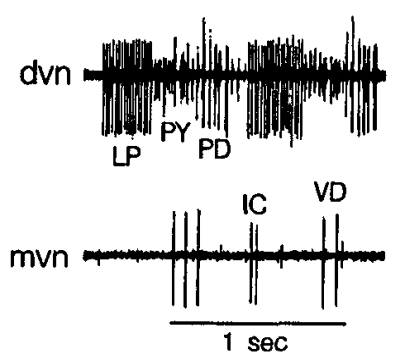

B

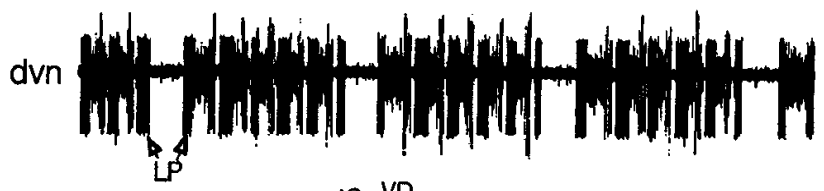
mvn
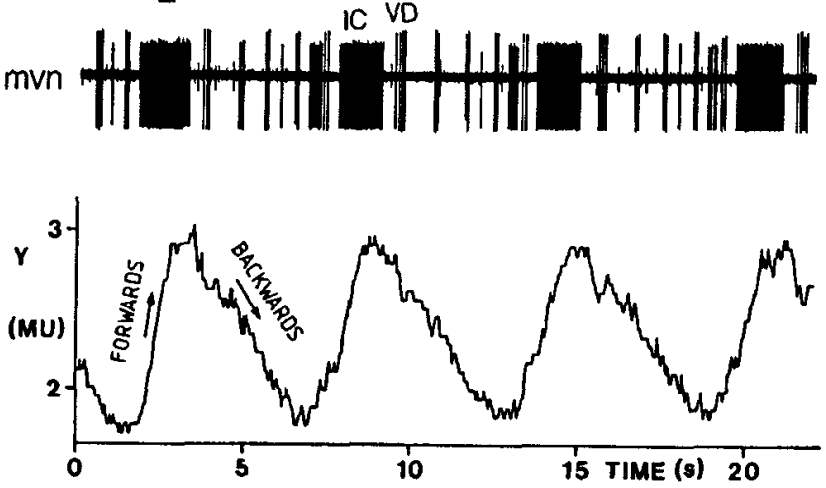

Figure 9. Effect of proctolin on lateral tooth movement: combined endoscope and extracellular recordings from an in situ preparation. $A$, At the beginning of superfusion of the STG with $10^{-6} \mathrm{M}$ proctolin, the pyloric rhythm is enhanced, with $L P$ firing $\sim 20$ spikes/burst. At this time, movements of the lateral teeth were seen and the cardiopyloric valve and accessory teeth moved in pyloric time (not shown). $B$. Several minutes after proctolin application, $I C$ has switched into a gastric firing pattern of long bursts, which causes the forward launching of the lateral teeth. Note that no other neurons are firing during the $I C$ burst. The movement plot illustrates the tooth position simultaneously with the recordings directly above.

9. This clearly shows a large forward movement of the lateral teeth during the IC plateau. This was not expected because gm5a, one of the three muscles innervated by the IC neuron, runs parallel and adjacent to the LG-innervated gm $5 \mathrm{~b}$ muscle. We were surprised that IC activity did not cause a large closure of the lateral teeth. One possible explanation for this may lie in the fact that each of the three muscles (one gastric, one cardiopyloric valve, and one cardiac valve) innervated by the IC neuron shows different facilitory and antifacilitory properties (Weimann et al., 1991). Therefore, the behaviors produced by different patterns of activity in the IC will be complex. In a complete gastric rhythm in which MG, LG, and IC are all firing in gastric time, the teeth can be pulled forward during the IC phase and closed during the $\mathrm{LG} / \mathrm{MG}$ phase.

\section{New role for gastric mill neurons}

The three-dimensional relationships of the arrangements of the teeth and ossicles can lead to additional movements that are not intuitively obvious. This can be illustrated by the movements produced by the GM motor neurons. The four GM neurons innervate three groups of extrinsic muscles: gm lab, gm2, and gm 3 bc (Weimann et al., 1991). The gm 1 muscles originate
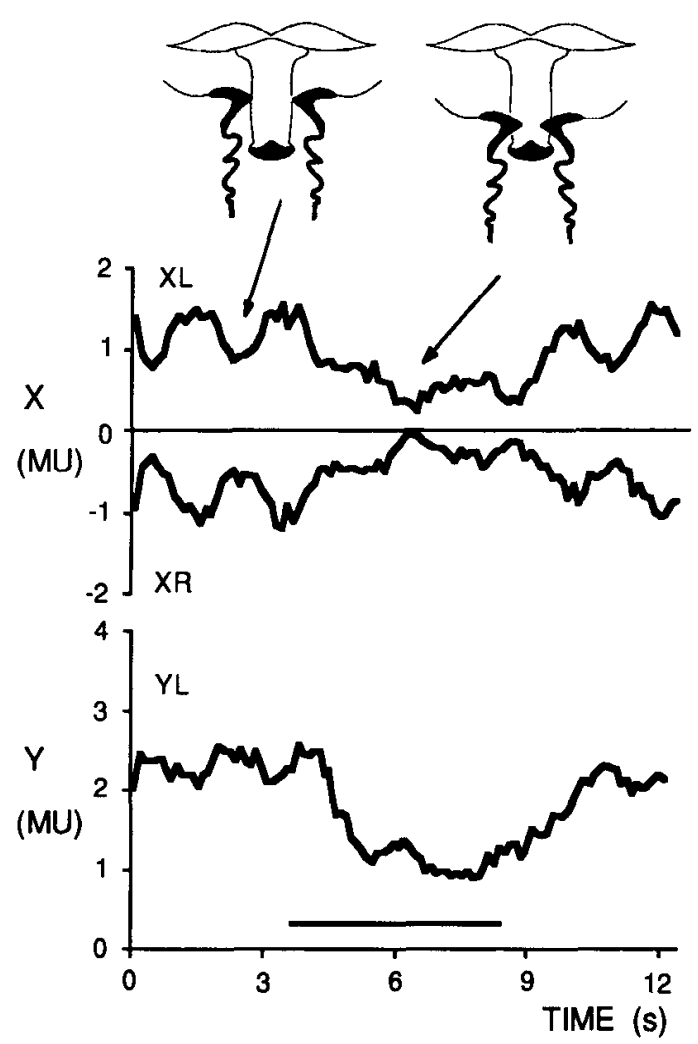

Figure 10. GM neurons close the lateral teeth. The pictures show the positions of the teeth at the times indicated by the arrows on the plots of $x$ - and $y$-positions of the lateral teeth. During weak spontaneous LG firing, the left $(X L)$ and right $(X R)$ teeth closed about $0.5 \mathrm{MU}$ and were pulled backward about 0.25 MU. A GM neuron was fired at $50 \mathrm{~Hz}$ for $4.75 \mathrm{sec}$ (horizontal bar). The lateral teeth moved closer to the midline $(0 \mathrm{MU})$ and were pulled back toward the tip of the medial tooth that is at position $\mathrm{MU}=0,0$. The second drawing shows the positions of the teeth during GM stimulation. Notice that GM activity nearly doubled the movement of the lateral teeth.

at the carapace behind the eye stalks and insert onto ossicle II, which is part of the hinge for the medial tooth (Fig. 2). In the intact crab, bursts of action potentials in the GM motor neurons cause the gm 1 and gm 2 muscles to contract, providing the power stroke for the medial tooth.

The gm 2 and gm $3 b c$ muscles that are innervated by the GM neurons insert onto ossicles III and IV. These ossicles are mechanically coupled to the lateral teeth, such that GM activity also moves the lateral teeth (Fig. 10). Specifically, strong GM activity causes the lateral teeth to move posteriorly (y-direction). This movement is the grind phase of chewing in which the cusps of the lateral teeth grind backward along the file of the medial tooth in the lobster (Heinzel, 1988a). Our observations confirm that the GM innervated gm 2 and gm $3 b c$ muscles cause the grinding movement. Surprisingly, the lateral teeth are also closed by the firing of GM (Fig. 10).

Plotted in the first panel of Figure 10 are the $\mathrm{X}$-coordinates of the tips of the left (XL) and right (RL) lateral teeth before, during, and after depolarization of a GM motor neuron (vertical bar). The GM neuron was depolarized for $4.75 \mathrm{sec}$ and fired at a rate of $50 \mathrm{~Hz}$. In the second panel are the Y-coordinates of the left (YL) tooth measured in medial tooth units (MU) where $1 \mathrm{MU}$ is half the width of the medial tooth. The right tooth produced the same movement as the left tooth. The two sketches 
show the position of the lateral teeth with respect to the medial tooth during a mild LG-induced bite (first drawing) and the position of the teeth during depolarization of a GM motor neuron (second drawing). It is clear that GM activity enhanced the movement of the lateral teeth even though the firing rate of the LG neuron did not change. Thus, the GM neurons not only produce the grind phase but also augment the LG/MG-induced cut phase of the cut and grind mode of chewing. Qualitatively similar results were obtained in eight neurons; however, the amount of movement varied.

A summary diagram indicating the movements that result from activity in individual neurons is shown in Figure 11 . The arrows indicate the average or predominant movements caused by each motor neuron. Certain conclusions about the roles of individual neurons in the control of movements of the gastric mill can be made. Previously, it was known that the GM motor neurons innervate muscles (gm $1 \mathrm{ab}, \mathrm{gm} 2$ ) that produce the power stroke (protraction) of the medial tooth (Selverston and Moulins, 1987). We now see that the GM neurons can also retract and close the lateral teeth (Fig. 10). Second, the DG motor neuron innervates the gm 4 muscle (Fig. $2 B$ ) that controls the return stroke (retraction) of the medial tooth. When the DG neuron fires gastric-timed bursts but the other neurons are all firing in pyloric time, it may function to load the pyloric chamber. Third, the lateral posterior gastric motor neurons innervate muscles that open the lateral teeth. Fourth, the LG and MG neurons innervate muscles that close the lateral teeth. We now see that MG closes the tips of the teeth. When LG fires in short bursts, it also closes the tips of the teeth. However, when $\mathrm{LG}$ fires in long bursts, it additionally closes the serrated edges of the lateral tecth. Morcover, short, pyloric-timed activity patterns of even 2 or 3 spikes/burst in MG and LG are sufficient to produce pyloric-timed pumping of the lateral teeth, and to maintain muscle tone that aids in strong gastric movements (Fig. 8). Fifth, the IC neuron, classically considered a pyloric neuron, contributes to lateral tooth movement when firing in either pyloric time or gastric time (Figs. 6, 9), in addition to closing the accessory teeth and the cardiopyloric valve. The VD neuron opposes the pyloric actions of the IC neuron. Interestingly, the anterior median neuron usually considered part of the gastric mill pattern generator did not appear to have any effect on the movement of the gastric mill complex.

\section{Discussion}

The mechanisms by which rhythmic behaviors are produced and modulated have been extensively studied using in vitro preparations of the stomatogastric nervous system (Harris-Warrick and Marder, 1991). One of the most striking results from work of recent years in the stomatogastric nervous system is the highly variable number of motor patterns seen in the presence of different neuromodulatory environments (Marder and Weimann, 1992). In fact, some have wondered that such widely variable motor patterns seem unnecessary for the accomplishment of the apparently simple task of eating. Without direct behavioral observations it is impossible to know for certain whether all of the states found in in vitro studies are part of the behavioral repertoire of the animal. Indeed, one might imagine that the actual physical and mechanical constraints present in the animal might provide sensory or other feedback that could restrict the variability in motor patterns seen in intact animals to a small subset of those freely expressed in in vitro preparations. However, the results from the experiments reported here

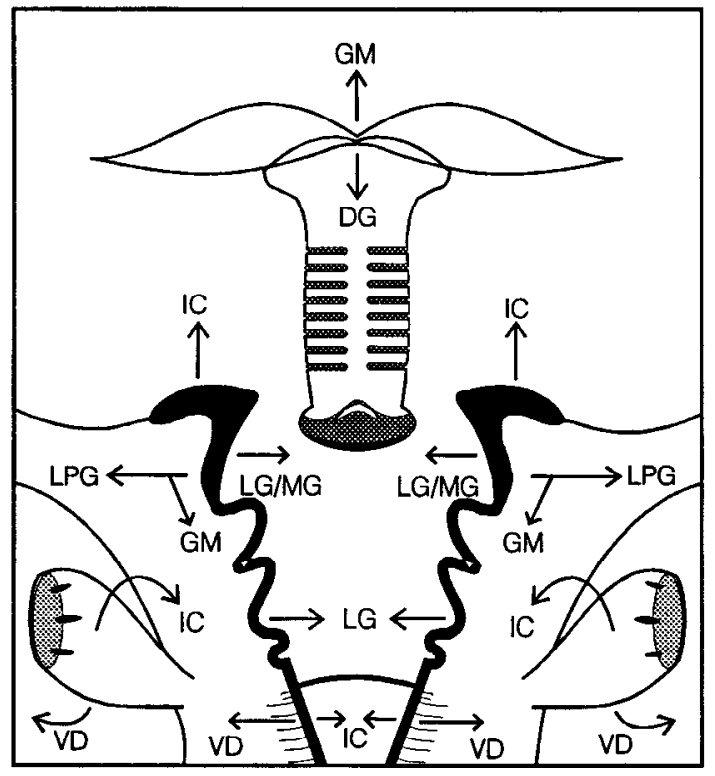

Figure 11. Summary diagram indicating the movements produced by activity in the indicated neurons. This summary combines information from spontaneous activity, modulator induced activity, and current injection into the soma.

are not consistent with that view. Instead, our data argue that many variants of the motor patterns that have been seen in vitro are likely to produce important and relevant behaviors, although without direct observation of the movements it would have been quite difficult to imagine what these were.

Given the organization of the crustacean foregut, it is far from trivial to relate motor patterns to movements because of the incompletely understood nonlinear transfer functions between the different motor patterns and the movements of the behaving animal. First, the stomach itself is a complex series of hinges, levers, and fulcrums consisting of ossicles and teeth (Maynard and Dando, 1974). Therefore, a given muscle or muscle group can produce movements that are quite difficult to predict (Figs. 8-10). Second, many of the synapses made by the motor neurons onto stomach muscles show considerable frequency-dependent modifications, such as facilitation and depression (Govind et al., 1975; Hooper et al., 1986; Weimann et al., 1991). Therefore, even subtle changes in the number or timing of motor neuron action potentials in a burst may evoke considerably different amounts of movement or tension generation. Third, in the presence of some modulatory substances, at least some of the muscles are likely to display myogenic properties (Lingle, 1981; Meyrand and Moulins, 1986; Meyrand and Marder, 1991), which can greatly amplify the movements evoked by a given neural input. Fourth, a given fictive motor pattern is an event in an open loop system that can be substantially modified by sensory feedback under the closed loop conditions in a behaving animal. Therefore, it will be necessary to use the methods pioneered in this article to characterize the movements associated with a large variety of motor patterns, including those produced by modulatory substances and stimulation of sensory neurons. This article provides only the first step in an ongoing line of investigation that will almost certainly produce additional novel findings.

One of the most puzzling observations from in vitro experiments was that many of the gastric mill motor neurons fire in 
time with the pyloric rhythm when a full gastric rhythm is absent (Weimann et al., 1991). The endoscopic observations reported here showed that the lateral teeth display pyloric-timed movements, as well as the strong gastric-timed closures that were previously described in Panulirus interruptus (Heinzel, 1988a). The presence of these pyloric-timed movements of the teeth demonstrates that the switches of activity patterns seen in vitro are behaviorally significant. Moreover, it is clear that the different regions of the stomach are linked much more tightly than hitherto appreciated, suggesting that it may not be advisable to treat the pylorus and gastric mill as functionally independent structures. Importantly, the ability to record and manipulate electrical activity and movement simultaneously makes it clear that because of the mechanical structure of the stomach, a given movement often results from the cooperative activity of scveral neurons, some of which may be classically members of the pyloric network, while others may be those classically considered gastric network neurons.

When the LG and MG neurons fire in time with the pyloric rhythm, they often only fire only several spikes per burst (Weimann et al., 1991). In this article we demonstrate that when the LG and MG neurons fire only 2 or 3 spikes/burst in time with the pyloric rhythm, these few spikes are sufficient to produce pyloric-timed movements of the lateral teeth (Figs. 7, 8). These data demonstrate that LG activity is able to elicit movements over a large range, from short, pyloric-timed bursts of few spikes to long bursts typical of a full gastric rhythm. Interestingly, the simultaneous movement and electrophysiological recordings shown in Figure 6 show that full closure of the lateral teeth was produced by modest gastric bursts in LG. One of the issues that it will be possible to resolve in the future is the relationship between burst intensity and movement as the period of the gastric rhythm is varied.

The IC and VD neurons are "pyloric" neurons that switch into gastric time. We now see that the IC contributes to the movements of the lateral teeth when it fires in either pyloric or gastric time. Interestingly enough, we failed to observe any movement associated with pyloric-timed activity in the GM neurons, although in this case, the pyloric-timed activity is likely to maintain a basal level of facilitation at the neuromuscular junctions (Weimann et al., 1991) that will potentiate the movement produced by a gastric burst. Additionally, although low levels of pyloric-timed activity in some gastric neurons may not produce discrete contractions, they may play a role in maintaining muscle tone that keeps the stomach in its proper threedimensional configuration. Such activity may easily turn into large-scale movements if the muscles change their properties under the influence of modulatory substances (Lingle, 1981; Meyrand and Marder, 1991).

In summary, the experiments described in this article demonstrate that it is possible to correlate specific activity patterns of stomatogastric motor neurons with movements of the gastric mill. In the future it will be interesting to modify the activity of a single STG neuron during different ongoing behaviors. In this way it will be possible to determine how the movement actually produced by each neuron depends dynamically on the full patterns of activity in the STG networks. We have already seen that the full range of behaviors is much richer than previously described, and that many of the forms of modulated motor patterns produced by the STG are likely to be behaviorally important, in ways that are evident once they can be seen, but were impossible to envision otherwise. Further work will be required to characterize completely the full complement of movements in the gastric mill, and the interacting roles that these neurons play in shaping the repertoire of stomach movements.

\section{References}

Boyle MET, Turrigiano GG, Selverston AI (1990) An endoscopic analysis of gastric mill movements produced by the peptide cholecystokinin. Soc Neurosci Abstr 16:724.

Dickinson PS, Mecsas C, Marder E (1990) Neuropeptide fusion of two motor pattern generator circuits. Nature 344:155-158.

Dircksen H, Keller R (1988) Immunocytochemical localization of CCAP, a novel crustacean cardioactive peptide, in the nervous system of the shore crab, Carcinus maenas L. Cell Tissue Res 254:347-360.

Govind CK, Atwood HL, Maynard DM (1975) Innervation and neuromuscular physiology of intrinsic foregut muscles in the blue crab and spiny lobster. J Comp Physiol 96:185-204.

Harris-Warrick RM, Marder E (1991) Modulation of networks for behavior. Annu Rev Neurosci 14:39-57.

Hartline DK, Maynard DM (1975) Motor patterns in the stomatogastric ganglion of the lobster Panulirus argus. J Exp Biol 62:405420.

Heinzel HG (1988a) Gastric mill activity in the lobster. I. Spontaneous modes of chewing. J Neurophysiol 59:528-550.

Heinzel HG (1988b) Gastric mill activity in the lobster. II. Proctolin and octopamine initiate and modulate chewing. J Neurophysiol 59: $551-565$.

Heinzel HG (1990a) The cooperation of several oscillators in the stomatogastric system of the crab Cancer pagurus. In: Frontiers in crustacean neurobiology (Wiese K, Krenz WD, Tautz J, Reichert H, Mulloney B, eds), pp 455-462. Basel: Birkhäuser.

Heinzel HG (1990b) Modulation and sensory control of the crustacean gastric mill. In: Neural mechanisms of behavior (Erber J, Menzel R, Pfluger H, Todt D, eds), pp 61-66. Stuttgart: Thieme.

Heinzel HG, Selverston AI (1988) Gastric mill activity in the lobster III. Effects of proctolin on the isolated central pattern generator. $J$ Neurophysiol 59:566-585.

Heinzel HG, Weimann JM (1990) Combined endoscopic and electrophysiological recordings of multiple STG rhythms in intact crabs, Cancer pagurus. Soc Neurosci Abstr 16:725.

Hermann A (1979a) Generation of a fixed motor pattern. I. Details of synaptic interconnections of pyloric neurons in the stomatogastric ganglion of the crab, Cancer pagurus. J Comp Physiol 130:221-228.

Hermann A (1979b) Generation of a fixed motor pattern. II. Electrical properties and synaptic characteristics of pyloric neurons in the stomatogastric ganglion of the crab, Cancer pagurus. J Comp Physiol 130:229-239.

Hermann A, Dando MR (1977) Mechanisms of command fibre operation onto bursting pacemaker neurones in the stomatogastric ganglion of the crab, Cancer pagurus. J Comp Physiol 114:15-33.

Hooper SL, Marder E (1987) Modulation of the lobster pyloric rhythm by the peptide proctolin. J Neurosci 7:2097-2112.

Hooper SL, Moulins M (1989) Switching of a neuron from one network to another by sensory-induced changes in membrane properties. Science 244:1587-1589.

Hooper SL, O'Neil MB, Wagner RL, Ewer J, Golowasch J, Marder E (1986) The innervation of the pyloric region of the crab, Cancer borealis: homologous muscles in decapod species are differently innervated. J Comp Physiol [A] 159:227-240.

Katz PS, Harris-Warrick RM (1991) Recruitment of crab gastric mill neurons into the pyloric motor pattern by mechanosensory afferent stimulation. J Neurophysiol 65:1442-1451.

Lingle C (1981) The modulatory action of dopamine on crustacean foregut neuromuscular preparations. J Exp Biol 94:285-299.

Marder E, Hooper SL (1985) Neurotransmitter modulation of stomatogastric ganglion of decapod crustaceans. In: Model neural circuits and behavior (Selverston AI, ed), pp 319-337. New York: Plenum.

Marder E, Nusbaum MP (1989) Peptidergic modulation of the motor pattern generators in the stomatogastric ganglion. In: Perspectives in neural systems and behavior (Carew TC, Kelley D, eds), pp 73-91. New York: Liss.

Marder E, Weimann JM (1992) Modulatory control of multiple task processing in the stomatogastric nervous system. In: Neurobiology of motor progamme selection: new approaches to mechanisms of be- 
havioral choice (Kien J, McCrohan C, Winlow B, eds), pp 3-19. Oxford: Pergamon.

Marder E, Hooper SL, Siwicki KK (1986) Modulatory action and distribution of the neuropeptide proctolin in the crustacean stomatogastric nervous system. J Comp Neurol 243:454-467.

Maynard DM, Dando MR (1974) The structure of the stomatogastric neuromuscular system in Callinectes sapidus, Homarus americanus and Panulirus argus (Decapoda Crustacea). Philos Trans R Soc Lond [Biol] 268:161-220.

Meyrand P, Marder E (1991) Matching neural and muscle oscillators: control by FMRFamide-like peptides. J Neurosci 11:1150-1161.

Meyrand P, Moulins M (1986) Myogenic oscillatory activity in the pyloric rhythmic motor system of crustacea. J Comp Physiol 158: 489-503.

Meyrand P, Simmers J, Moulins M (1991) Construction of a patterngenerating circuit with neurons of different networks. Nature 351:6063.

Morris J, Maynard DM (1970) Recordings from the stomatogastric nervous system in intact lobsters. Comp Biochem Physiol 33:969974.

Mulloney B, Selverston AI (1974a) Organization of the stomatogastric ganglion in the spiny lobster. I. Neurons driving the lateral teeth. $\mathbf{J}$ Comp Physiol 91:1-32.

Mulloney B, Selverston AI (1974b) Organization of the stomatogastric ganglion in the spiny lobster. III. Coordination of the two subsets of the gastric system. J Comp Physiol 91:53-78.

Nagy F, Dickinson PS, Moulins M (1988) Control by an identified modulatory neuron of the sequential expression of pleateau properties of, and synaptic inputs to, a neuron in a central pattern generator. J Neurosci 8:2875-2886.

Nusbaum MP, Marder E (1989a) A modulatory proctolin-containing neuron (MPN). I. Identification and characterization. J Neurosci 9:1591-1599.

Nusbaum MP, Marder E (1989b) A modulatory proctolin-containing neuron (MPN). II. State-dependent modulation of rhythmic motor activity. J Neurosci 9:1600-1607.

Powers LW (1973) Gastric mill rhythms in intact crabs. Comp Biochem Physiol [A] 46:767-783.

Rezer E, Moulins M (1983) Expression of the crustacean pyloric pattern generator in intact animals. J Comp Physiol 153:17-28.

Rezer E, Moulins M (1992) Humoral induction of pyloric rhythmic output in lobster stomatogastric ganglion: in vivo and in vitro studies. J Exp Biol 163:209-230.

Selverston AI, Moulins M (1987) The crustacean stomatogastric system. Berlin: Springer.

Stangier J, Hilbich C, Dircksen H, Keller R (1988) Distribution of a novel cardioactive neuropeptide (CCAP) in the nervous system of the shore crab, Carcinus maenas. Peptides 9:795-800.

Weimann JM (1992) Multiple task processing in neural networks: numerous central pattern generators in the stomatogastric nervous system of the crab, Cancer borealis. PhD thesis, Brandeis University.

Weimann JM, Meyrand P, Marder E (1990) Neurons that participate in several behaviors. In: Frontiers in crustacean neurobiology (Wiese K, Krenz W-D, Tautz J, Reichert H, Mulloney B, eds), pp 424-430. Basel: Birkhäuser.

Weimann JM, Meyrand P, Marder E (1991) Neurons that form multiple pattern generators: identification and multiple activity patterns of gastric/pyloric neurons in the crab stomatogastric system. J Neurophysiol 65:111-122.

Weimann JM, Heinzel HG, Marder E (1992) Crustacean cardioactive peptide activation of the pyloric network in the STG of the crab, Cancer borealis. Soc Neurosci Abstr 18:1056. 